\title{
Jorge Alberto Manrique. In memoriam
}

\author{
Luciano Ramírez Hurtado*®
}

Ramírez Hurtado, L. (2017). Jorge Alberto Manrique. In memoriam [Obituario]. Investigación y Ciencia de la Universidad Autónoma de Aguascalientes, 25(71), 102-103.

El pasado 2 de noviembre de 2016, Día de Muertos, falleció en la capital del país el gran historiador, escritor, crítico de arte e investigador emérito Jorge Alberto Manrique Castañeda, a la edad de 80 años. Originario de la Ciudad de México (Azcapotzalco, 17 de julio de 1936), tuvo una prolífica vida académica, pues escribió mucho, formó varias generaciones de historiadores e hizo grandes aportaciones a la historiografía.

Jorge Alberto Manrique estudió en la Facultad de Filosofía y Letras de la Universidad Nacional Autónoma de México donde se graduó en 1961, en una época en que la profesionalización de la ciencia de la Historia era una realidad; no pocos de sus maestros fueron españoles republicanos de la talla de José Gaos, Wenceslao Roces, Luis Villoro, Juan. A. Ortega y Medina, que vinieron a nuestro país a enriquecer disciplinas como la Historia, la Filosofía, la Estética y la Filosofía de la Historia. De una u otra forma fue heredero y recuperó el legado de excelentes maestros mexicanos como Manuel Toussaint, Justino Fernández, Ida Rodríguez Prampolini y, desde lvego, Edmundo O'Gorman, de quien le viene la corriente historicista. Entre sus compañeros, estupendos historiadores, destacan Elisa Vargas Lugo, Isabel Estrada de Gerlero, Pedro Rojas, Aurelio de los Reyes, Álvaro Matute y el ya fallecido Eduardo Blanquel. Discípulos de renombre, solo por citar uno, a Rogelio Ruiz Gomar.

Se dedicó a dar cátedra en la propia Facultad de Filosofía y Letras, tanto en pregrado como en posgrado, donde figuró como profesor y tutor tanto en la Licenciatura en Historia como en la Maestría y en el Doctorado en Historia del Arte. Obtuvo una

\footnotetext{
* Departamento de Historia, Centro de Ciencias Sociales y Humanidades, Universidad Autónoma de Aguascalientes. Av. Universidad 940, Ciudad Universitaria, C. P. 20131, Aguascalientes, Aguascalientes, México. Correo electrónico: Iramirez@correo.vaa.mx

Autor para correspondencia
}

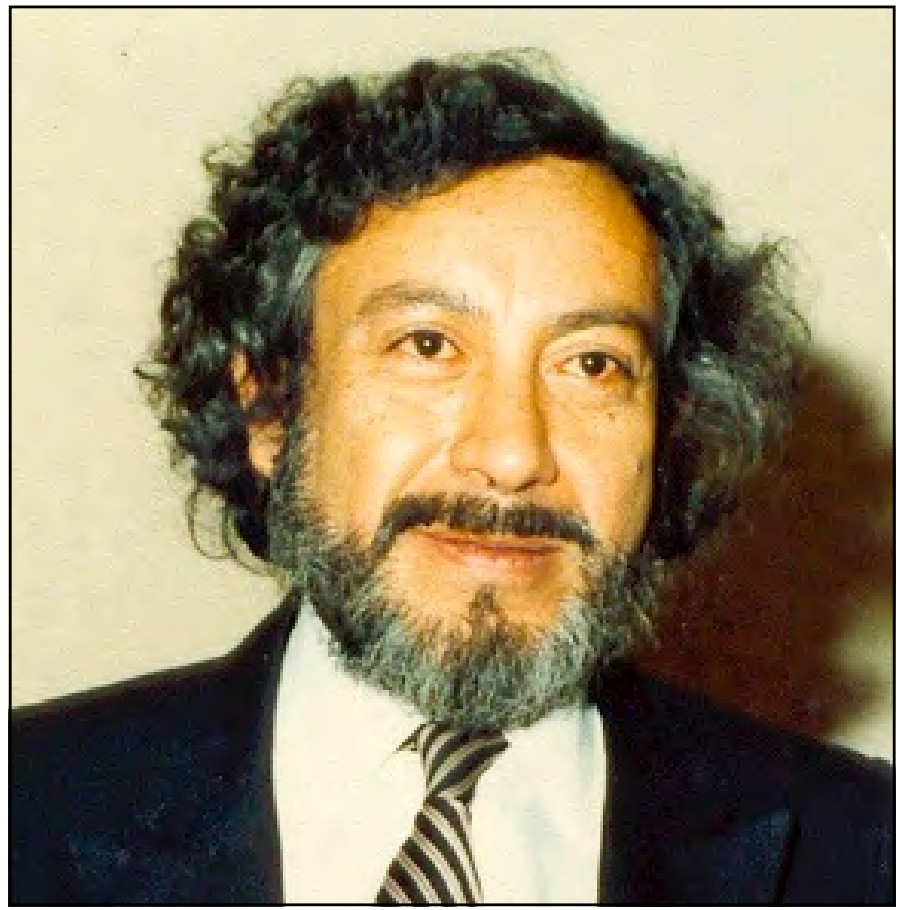

El Dr. Jorge Alberto Manrique en 1984.

Fotografía modificada de la tomada por P. Cuevas y proporcionada por la Dra. Julieta Ortiz Gaitán.

plaza en el Instituto de Investigaciones Estéticas en 1968, antes llamado Laboratorio del Arte, donde tuvo a la mano una maravillosa biblioteca y un gigantesco banco de imágenes a su disposición. A lo largo de su vida académica vivió con intensidad en el aula, en su cubículo, en viajes de estudio, en eventos académicos, pero sobre todo en los archivos, pues fue un gran investigador.

Jorge Alberto Manrique, historiador, teórico y crítico de arte, se interesó prácticamente en todas las épocas del pasado mexicano. Con espíritu crítico, desmontó una serie de mitos que había en torno a ciertos periodos y movimientos artísticos. Fue director fundador del Museo Nacional de Arte, 
en la calle de Tacuba —plaza Manuel Tolsá-que alberga una de las colecciones más importantes de México. También dirigió el Museo de Arte Moderno, ubicado en Chapultepec.

Entre sus publicaciones destacan: El geometrismo mexicano, México, UNAM, 1975 (en colaboración); La dispersión del manierismo, México, UNAM, 1980; Ángel Zárraga, Cámara Nacional de la Industria de la Construcción, 1984; Una mujer en el arte mexicano, México, UNAM, 1987; Historia del urbanismo en el mundo hispánico (coautor), México, 1990; Veracruz, ciudad del mar (coautor), Jalapa, Instituto Veracruzano de Cultura, 1991.

Fue invitado para ser el coordinar general de Historia del Arte Mexicano, magna obra en 16 volúmenes profusamente ilustrada, publicada bajo los auspicios de la Editorial Salvat en coedición con la Secretaría de Educación Pública y el Instituto Nacional de Bellas Artes. En la presentación escribió: "El arte es, en efecto, un modo de tener conciencia de nosotros mismos y del pasado que nos constituye y nos une" (Manrique, 1982, p. 2).

A su vez, invitó a Beatriz de la Fuente para coordinar la parte correspondiente al arte prehispánico; a Elisa Vargas Lugo le tocó el arte novohispano; del arte del México independiente del siglo XIX se ocupó Fausto Ramírez; y el propio Jorge Alberto Manrique se encargó del arte contemporáneo, desde la aparición del muralismo en los tempranos años de la década de los veinte hasta mediados de la octava década del siglo pasado.

Muchos de sus escritos publicados inicialmente como artículos en revistas especializadas en historia e historia del arte en México, Francia, Italia, España, Polonia, Alemania Federal, Estados Unidos, Brasil, Argentina y Colombia, compilados por sus discípulos Martha Fernández y Margarito Sandoval (con la colaboración de Edgardo Ganado Kim y siete personas más) fueron publicados en el año 2000 y reimpresos en 2004 por el Instituto de Investigaciones Estéticas de la UNAM, en cinco tomos bajo el título: Una visión del arte y de la historia, que dan cuenta de las visiones, versiones, verdades y posturas teóricas y metodológicas que han guiado el conocimiento de esas disciplinas durante la segunda mitad del siglo XX. En la solapa de esta obra se lee:

\begin{abstract}
Jorge Alberto Manrique es uno de los historiadores del arte más importantes del México contemporáneo y uno de los más respetados y creativos. Su sólida formación humanista le ha permitido unir de manera clara y elocuente dos campos del conocimiento: la historia y la historia del arte. Historicista convencido, ha generado un importante cambio en los estudios de arte y ha contribuido a convertir la crítica de arte en una disciplina. Investigador riguroso, nuestra historia del arte le debe textos fundamentales, algunos ya considerados clásicos. Maestro excepcional, ha sido formador de varias generaciones de historiadores de arte, mediante la asesoría de tesis y las cátedras que ha impartido principalmente en la Facultad de Filosofía y Letras de la UNAM, pero también en otras instituciones nacionales y extranjeras. Fue director de la Facultad de Filosofía y Letras de la Universidad Veracruzana, del Instituto de Investigaciones Estéticas...
\end{abstract}

Uno de sus discípulos es el Dr. Benjamín Flores Hernández, profesor-investigador del Departamento de Historia en la Universidad Autónoma de Aguascalientes, a quien le dirigió su tesis acerca de la historia de la fiesta brava en el paso del toreo a caballo al toreo a pie en Nueva España.

Conocí al Mtro. Jorge Alberto Manrique en el año 2001, en la presentación de proyectos de los doctorandos, en uno de los salones del Instituto de Investigaciones Estéticas de la UNAM; de trato amable y cordial, platiqué brevemente con él, le comenté sobre el tema que estaba trabajando bajo la dirección del Dr. Aurelio de los Reyes, mostrando un vivo interés.

Varios de sus textos son lectura obligada para mis alumnos, en una de las materias que imparto en la Universidad Autónoma de Aguascalientes en la Licenciatura en Historia, en quinto semestre, me refiero al curso "Historia del arte mexicano".

Manrique fue miembro de número de la Academia Mexicana de la Historia, de la Academia de las Artes y de la Academia Mexicana de Ciencias. Fuereconocido con varios premios y reconocimientos en nuestro país y en el extranjero; la última el 6 de septiembre del año pasado. Su incuestionable labor docente, sus valiosas aportaciones a la crítica de arte, sus investigaciones de alta calidad son sin duda suma y reflejo, un parteaguas en la vida del México contemporáneo. 